\title{
What Impact Will REACH Have on Consumer Protection?
}

\author{
Peter Bormann, Dag Kappes, Paul Odermatt, and Eva Reinhard*
}

\begin{abstract}
In the last decades, several regulatory approaches have been taken in order to ensure the safe management of chemicals. The major drawback of the current EU and Swiss legislations is the distinction made between so-called 'existing' and 'new' chemicals, based on their time of marketing. While all new chemicals have to be tested for potential harmful effects to human health and the environment, there exist no similar requirements for the approximately $30^{\prime} 000$ existing chemicals found on the market. Considering that $26 \%$ of existing and $60 \%$ of new chemicals that have been so far officially assessed and listed in Annex I of Directive 67/548/EEC, have irritating and/or sensitizing effects, it has to be assumed that several thousand chemicals consumers are exposed to are not appropriately labelled with respect to potential risks. REACH is intended to create a system which is based on information about all chemicals. Especially for chemicals marketed at high quantities REACH will indeed improve the current situation and eliminate safety gaps. Chemicals marketed at lower quantities, however, will not be subject to equally profound assessments. It remains to be seen whether substance-tailored requirements will compensate for the weaknesses of a quantity-based safety and information system, especially in respect to consumer protection. REACH will generate a lot of knowledge, some of which will be publicly available. However, the newly created knowledge refers mostly to substances. No central database containing information about products on the market, in particular their compositions, is planed. Crucially, major parts of risk assessments and identifications will be performed by industry that therefore has to take a major responsibility onboard. The success of REACH will depend on the way the private sector will manage this important safety system and whether consumers and other stakeholders can build up trust and confidence. The former Swiss Toxicity Law outmatched the current legislation and REACH in several aspects. It did not distinguish between existing and new chemicals. The main responsibility was clearly placed on the authorities, building up trust among all stakeholders, including the public. The marketing of products was mainly dependent on their toxicity. The enforcement was strictly controlled which generally led to substitutions of toxic substances with less toxic ones, especially in consumer products. However, maintaining a nation-specific regulation in today's global marketplace proved to be inappropriate. Therefore, in 2005 Switzerland adopted a new legislation largely harmonized with the specific EU-Directives. REACH forces Switzerland once again to reconsider its legislation.
\end{abstract}

Keywords: Chemicals policy · Consumer protection - Product register · REACH · Swiss Toxicity Law

\section{Introduction}

Each day, consumers are in contact with chemicals. Consciously, when using chemical products such as cleansing agents, decalcifiers or paint. Mostly unconsciously, for example when touching drinking bottles or using articles that release chemicals such as room deodorants. For decades the common notion was that adequate measures were in place to protect human health as well as the environment from possible adverse effects of hazardous chemicals and that chemicals placed on the market cause no harm when used correctly. This confidence was undermined by different findings. A largely unaccountable increase in cancer, infertility and sensitization among the general public, in combination with concern-causing findings of persistent chemicals in the environment and in the human body reduced the public's trust in chemical corporations, authorities and adopted legal measures. To a certain extent the regulatory bodies have failed to communicate the regulatory loopholes and problems of the chemicals legislation in a transparent and understandable way to the public.

Against this background, the European Union has designed a new chemicals legislation called 'REACH' [1]. REACH stands for Registration, Authorisation and Evaluation of Chemicals. It aims at enhancing protection from intentionally produced chemicals. Further, it intends to fill the gaps in basic information available on substances, to minimise the costs of providing this data and to take precautionary action on the most problematic substances. At the same time REACH's objective is also to boost Europe's chemical industry.

This article outlines to what extent the current proposal of REACH has a better
Fax: +41313235486

E-Mail: eva.reinhard@bag.admin.ch
*Correspondence: Dr. E. Reinhard
Swiss Federal Office of Public Health Consumer Protection Directorate

Division of Chemical Products

$\mathrm{CH}-3003$ Bern 
chance than previous chemicals legislations to fulfil the promises given to unsettled consumers. The authors shed light on the success and/or failure of more than 30 years of consumer protection provided by chemicals legislations in Europe and in Switzerland. In Switzerland, the first federal chemicals regulation was put into force in 1972 [2]. On European level the implementation of harmonised chemicals legislation started in 1967 with the adoption of the dangerous substances directive [3]. The basic approach to protect human health and the environment from negative effects from chemicals differs considerably in the former Swiss system, in the current EU and in the future EU system. All three reflect the scientific knowledge and the economic interests of the respective time of their constitution.

\section{Progression of the Current EC Chemicals Legislation}

In the 1960s the six Member States of the European Economic Community decided to harmonize their widely differing national regulations on chemicals. The main objective was to facilitate Community trade. In addition, the need to protect in particular the health of workers handling dangerous chemicals was recognized. This resulted in the adoption of the Dangerous Substances Directive (DSD) [3] in 1967 which adopted common standardised provisions on classification, packaging and labelling of dangerous substances and introduced a list of 17 officially classified dangerous substances (Annex I of DSD). From the beginning, 67/548/EEC imposed the responsibility for the classification and labelling of most substances and all preparations on the manufacturer.

Over time, it became evident that additional measures were needed to control particular substances or groups of substances that were considered very toxic. Council Directive 76/769/EEC [4] that restricts the marketing and use of certain dangerous substances and preparations was originally adopted to implement the decision of the OECD to restrict polychlorinated biphenyls and terphenyls. Presently, 76/769/EEC restricts the trade of about 100 substances or groups of substances. In addition to substance-specific regulations, protection of non professional consumers was further improved by generally interdicting the supply of carcinogenic, mutagenic and reprotoxic substances $(\mathrm{c} / \mathrm{m} / \mathrm{r})$ of categories 1 and 2 to the general public.

It was the 6th Amendment of the DSD [5] which introduced in 1979, a notification scheme for 'new' substances and the European List of Notified Chemical Substances (ELINCS) was established. Any new substance placed on the market after that date was subjected to a prior study by the manufacturer or importer and a notification to the competent authorities. Substance-specific information depending on the quantity of the substance placed on the market had to be conveyed to the authorities. This allowed for a notification of a substance to one Member State to be then valid for the Community. Consequently, a list of 'existing' substances, the European Inventory of Existing Commercial Chemical Substances (EINECS) that comprises all substances marketed before September 1981, had to be set up. However, only the 7th Amendment of the DSD in 1992 [6] laid down uniform principles for risk assessment for new substances that included evaluation of potential risks for the consumer.

In order to ensure the protection of man and the environment also from the risks of existing substances appearing in the EINECS, the Council adopted in 1993 the existing substances regulation [7]. Manufacturers and importers had to submit information and test data on existing substances produced or imported in quantities exceeding ten tonnes to the Commission. Based on this information the Commission, in consultation with Member States, drew up priority lists with substances requiring special attention. Today, Member States are still carrying out risk assessments of the selected substances. The results of the evaluation and the recommended strategy for limiting risks have then to be adopted at Community level. Experience has shown that the chosen procedure is rather cumbersome and does not allow the evaluation of dangerous substances in the priority lists within the originally designated time-frames.

Up to 1973 preparations were neither subject to common regulations nor administrative provisions within the Community. Council Directive 73/173 [8] started to fill in the loophole and introduced provisions about the classification, packaging and labelling of dangerous solvents. The preamble mentioned the risk of toxicity and harmfulness of solvents and noted that such preparations were frequently used for domestic purposes either as solvents as such or as dilutants, cleaning products or degreasing agents. Solvents were followed by provisions on paints, varnishes, printing inks and adhesives in Council Directive 77/728 [9]. However, only in 1988, harmonised classification, packaging and labelling regulations for preparations containing at least one substance classified as dangerous were adopted [10]. Besides the elimination of barriers to trade, consumer protection was mentioned to be a central concern of the new Directive. It aimed to ensure protection of the public, including children, the visually handicapped and persons who come into contact with dangerous preparations at their workplace or in the pursuit of a hobby. Special attention was given to provisions concerning the label that was recognized as a basic tool for users, by giving them the initial essential concise information. To sum up, a legally binding strategy controlling in an integrative approach potentially dangerous substances and preparations exists for less than 20 years within the community.

\section{Experience and Current State of Chemicals Control in the EU}

Technical and scientific progress as well as increasing awareness of the need to ensure protection of man and the environment led to several adaptations of the various directives. This resulted in a voluminous and complex legislation that renders it very difficult to understand its consequential benefits. The new chemicals notification scheme guarantees a high level of safety and protection of consumers against dangerous new substances, in particular for those marketed at over ten tonnes per year. However, the extensive data requirements coupled with time consuming administrative measures led to the accusation of impeding innovation. Indeed, ELINCS lists 3827 substances which have been marketed at bigger quantities than $10 \mathrm{~kg}$ per year since September 1981 only. The consumers' confidence in the existing legislation is in particular hampered by the slow process of evaluating the risks of existing substances.

The European Commission's Joint Research Centre estimates that approximately $30^{\prime} 000$ existing substances, produced at more than one tonne per year, are actually on the market. For fewer than 100 of these substances a final risk assessment is available. Bodar et al. [11] evaluated 41 completed risk assessments for existing substances from the priority lists. They found that the predictability of possible risks was poor. Particularly for consumers, a great number of 'underestimations' and 'overestimations' were noted. Considering that less than $20 \%$ of the existing chemicals produced at over $1000 \mathrm{t} / \mathrm{y}$ have data publicly available at the level of the base set used for new chemicals marketed at one $t / y$ or above, the concern and distrust of consumers in the safety friendliness of industry and government provisions has to be taken seriously. In order to better understand the effect of mandatory data and risk assessments on the classification and concomitantly the regulation of chemicals, we analyzed quantitatively and qualitatively the substances listed in EINECS, ELINCS and Annex I of Council Directive 67/548/ EEC. Emphasis was placed on endpoints relevant for human health, such as carcinogenicity, mutagenicity, reproductive and chronic toxicity, as well as irritation and sensitisation. All searches were done in the 
database 'EINECS Plus 2006:1' published by the 'Office for Official Publications of the European Communities and SilverPlatter Information Ltd.'.

Annex I of Directive 67/548/EEC contains a list of harmonised classifications and labelling for substances or groups of substances. The list is regularly updated through adaptations to technical progress and contains at the moment 3362 entries. Revised and new classifications inserted to the list are proposed by the EU Environment Directorate-General, based on advice from the Technical Committee for Classification and Labelling with participation of experts from the Member States. Fig. 1 shows the number of substances in Annex I classified for their acute, corrosive, irritant, sensitizing, carcinogenic, teratogenic and chronic toxicity, respectively. Endpointspecific risk phrases were used to search the substance-specific classifications listed in Annex I. A substance being classified for several endpoints may appear in more than one bar. Within one bar, one particular substance is counted once only. Within substances classified for corrosive, irritating and sensitizing effects, damage caused by dermal exposure and adsorption is most relevant. For example, out of the $720 \mathrm{sub}-$ stances classified as sensitizing, solely 26 are exclusively sensitizing by inhalation. Out of 824 substances classified as irritating, only 30 are irritating exclusively to the respiratory system. The significance of the dermal exposure route is further supported by the fact that 1300 substances out of the 1456 classified as corrosive, irritating and/ or sensitizing may be used in consumer products (not shown). 2997 substances listed in Annex I are classified as dangerous to human health. Of those, 1895 are according to the legislation allowed to be included in consumer products (Fig. 1). The dermal exposure route seems to be significant for consumers compared to other routes of exposure, such as the ingestion or inhalation route. Furthermore, oral exposition is generally excluded by the correct use of consumer products. Skin exposure, however, is hardly prevented when using chemicals non-professionally. In comparison, 210 substances $(\mathrm{c} / \mathrm{m} / \mathrm{r}$ categories 3 ) with limited evidence of carcinogenic or other irreversible effects are allowed to be used in consumer products only. We further analyzed whether the percentage of substances classified as irritating and/or sensitizing differs among the officially classified EINECS and ELINCS substances. Fig. 2 and 3 show that within both groups, officially classified EINECS and ELINCS substances, the percentage of substances exerting effects by the dermal exposure route is $26 \%$ and $60 \%$, respectively. Considering the high number of not at all or only partially evaluated, classified and labelled existing chemicals the increas-

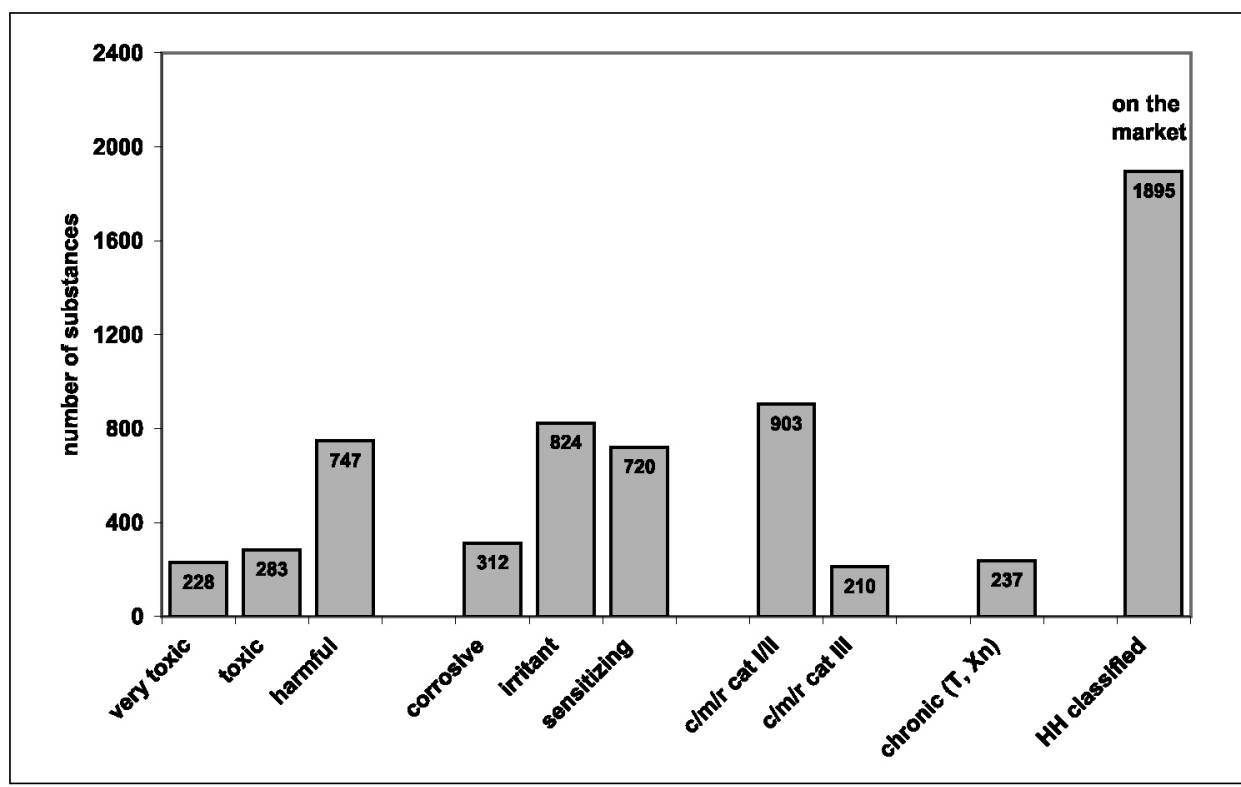

Fig. 1. Substances listed in Annex I of Directive 67/548/EEC classified for human health endpoints. R-Phrases were used to evaluate the number of substances classified for particular endpoints. Acute Toxicity: Very toxic (R26, R27, R28 and possible combinations thereof with or without R39); Toxic (R23, R24, R25 and possible combinations thereof with or without R39); Harmful (R20, R21, R22 and possible combinations thereof with or without R68); Corrosive (R34 and R35); Irritant (R36, R37, R38, R41 and possible combinations thereof); Sensitizing (R42 and R43). Carcinogenic, mutagenic and reprotoxic substances were taken together, categories 1 and 2 (c/m/r cat. 1 or 2 ; R45, R49, R46, R60, R61) were separated from category III (c/m/r cat. 3; R40, R68, R62, R63). Chronic Toxicity: Toxic (R23, R24, R25 and possible combinations thereof with R48); Harmful (R20, R21, R22 and possible combinations thereof with R48). 'HH classified' comprises all substances listed in Annex I classified for human health endpoints that are on the market (not classified as $\mathrm{c} / \mathrm{m} / \mathrm{r}$ cat. 1 or 2 and/or very toxic).

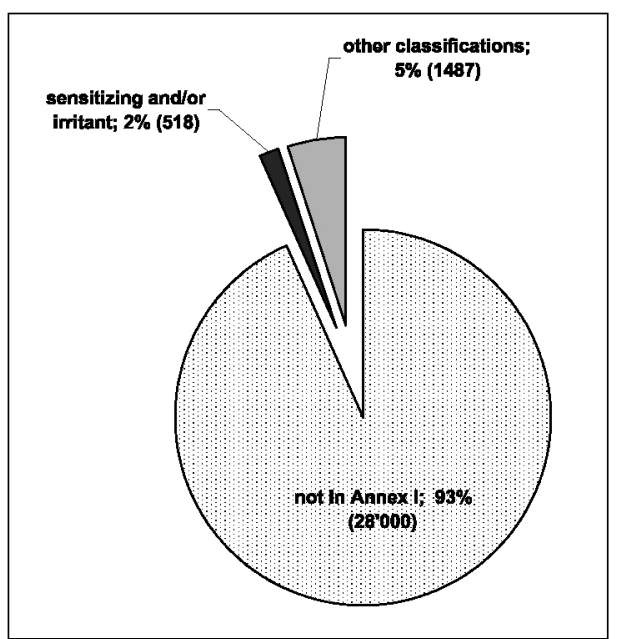

Fig. 2. Number of substances listed in EINECS that are assumed to be relevant for the market ( 30 '000 vs. 101106 total EINECS entries). EINECS substances that are listed in Annex I of Directive 67/548/EEC and classified for human health endpoints are indicated and separated into: Sensitizing and/or irritant (R36, R37, R38, R41, R42, R43 and possible combinations thereof) and 'other classifications' comprising all other substances that are classified for human health endpoints.

ing concern that daily exposure to hundreds of inadequately tested substances may have unwanted toxicological effects in the longrun may be justified.

Monitoring studies in several Member States showed considerable deficiencies

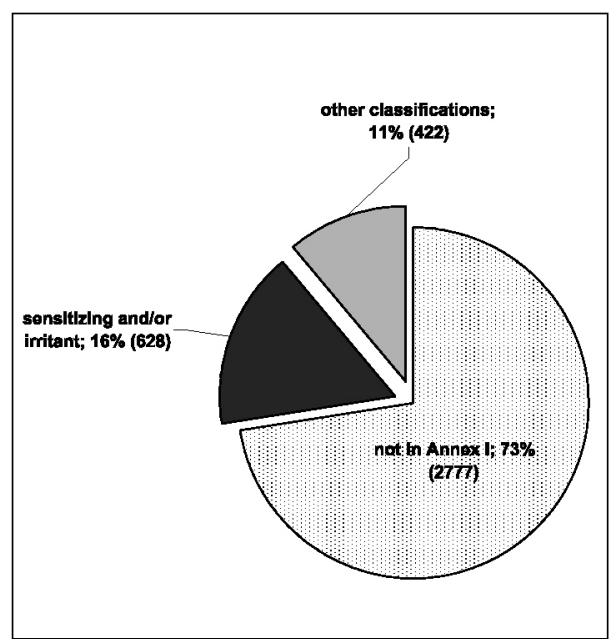

Fig. 3. Substances listed in ELINCS. ELINCS substances that are listed in the Annex $I$ of Directive 67/548/EEC and classified for human health endpoints are indicated and separated into: Sensitizing and/or irritant ( $R 36, R 37, R 38$, R41, R42, R43 and possible combinations thereof) and 'other classifications' comprising all other substances that are classified for human health endpoints.

in the indication of hazard on dangerous chemicals. The labelling of $60 \%$ of the preparations currently on the market, did not comply with the regulations [12] shedding a dubious light on industry's credibility and trustworthiness. 
Taken together, the intention of the Council to systematically evaluate and regulate all existing chemicals and thereby ensure the protection of man and the environment through the current legislation has not been realized up to this date. There is evidence that lack of data affects workers' and consumers' health. An increasing number of sensitisations against particular chemical substances have been noted. Consequently, the declaration requirements of sensitising substances in preparations were tightened, in particular for detergents [13]. However, the impact of daily exposure to non-labelled products based on no data is not known.

\section{REACH}

REACH is still under discussion. Whereas some argue that the foreseeable stringent provisions will have a painful impact on the competitiveness of EU companies in the global market, others complain about insufficient safety and protection measures for man and the environment. Despite the fact that the jury is still out, it is unlikely that major changes will be made at this stage and potential effects of the reformed chemicals management can be appraised.

For safety and protection purposes of consumers two aspects of REACH are most important. First of all, REACH will remove the distinction between existing and new chemicals and secondly, REACH includes requirementsforcommunicating information on chemical properties, and safe uses up and down the supply chain. REACH anticipates that information on all existing substances manufactured in, or imported into, the EU in tonnages of one tonne or more per year (approx. 30'000 substances) is available within twelve years of REACH entering into force. In addition, approx. 500 new substances will have to be registered per year.

Registration requirements vary by tonnage. Forsubstances manufacturedor imported in quantities below ten tonnes the dossier must include toxicological data about possible acute, corrosive, irritant, sensitizing and mutagenic effects. Much of the information generated by REACH will be made publicly available by the future agency in Helsinki. Thereby, REACH will lead to many more labelled products, better informed consumers and a generally higher standard of protection of human health and the environment - mainly by new and increased safety information on existing chemicals. Nevertheless, REACH contains certain alleviations that give toxicologists and authorities cause for concern. The current notification system for new chemicals asks for basic safety data, including skin irritation and sensitization above $100 \mathrm{~kg}$ per year and for a repeated dose toxicity ( 28 days) study above one $\mathrm{t} / \mathrm{y}$.
REACH, in contrast starts at one t/y only, resulting in a decrease of the standard of protection for new chemicals. Furthermore, the information which has to be supplied for the approximately 18'000 substances between one and ten tonnes per year is limited and does for example not include a repeated dose study (e.g. 28 day study) in animals. Without such a study, evaluation of systemic or organ specific effects or of the dose response is not possible [14]. Even for substances between 10 and 100 tonnes per year, a repeated dose toxicity study seems not to become mandatory, because waiving may be possible. Demands for cost reduction and protection of animals are legitimate. It has to be considered, however, that such demands may render appropriate risk assessment impossible. Also substances produced and marketed in low quantities may have unforeseen toxic effects in case of acute or continuous exposure. The concept of defining data requirements on quantity and exposure categories does not allow sufficiently understanding of the toxic potencies of particular substances.

REACH clearly imposes the main responsibility for chemical safety on the chemical manufacturer. He has to be able to prove that the specific chemical can be used safely, and how. All actors in the supply chain will be obliged to ensure the safety of the chemical substances they handle. Evaluation by authorities will be restricted to chemicals of particular concern. Similar to the current legislation, specific restrictions may be adopted for chemicals whose use poses unacceptable risks to human health or the environment for their production or use. Also classification and labelling measures will not considerably change under REACH. Consumers will not benefit from product information beyond the label or more labelled products. Unfortunately, with respect to consumer protection, also under REACH, articles, including articles releasing dangerous substances, do not have to be labelled. Accordingly, REACH does not provide measures to guarantee appropriate indoor air quality. Implementation of the globally harmonised system on Classification and Labelling [15] will neither improve the information about a product nor the protection level within Europe or Switzerland. Although REACH will generate a lot of information, no central data base for marketed products, including their compositions, is foreseen. Switzerland as well as some Member States profit from such data in great extent (see below).

\section{The Former Swiss Federal Law on Trade in Toxic Substances}

Switzerland adopted its first national chemicals legislation in 1972 [2]. Naturally, it was aimed at the protection of human and animal health from hazardous chemicals.
All chemicals and each chemical preparation had to be registered at the Federal Office for Public Health (FOPH) prior to marketing by sending in all available toxicological data. Based on this data and further investigations and expert knowledge, all chemicals were assessed by the FOPH. In accordance with their overall hazard the FOPH classified the toxic substances into one of five toxicity categories. The official classification of the toxicity class and the labelling as well as the chemical and product specific number visible on the label provided confidence to the consumers regarding the safety of chemicals.

As a requirement for the registration the complete composition of the product had to be submitted to the FOPH. The data was stored in an interactive product register containing ultimately confidential data of more than $350^{\prime} 000$ products. Besides the FOPH, the Swiss Toxicological Information Centre had access to this data. In case of intoxications or accidents the stored data helped to provide rapid product-specific treatments and take appropriate measures. Furthermore, the overview of all chemicals marketed in Switzerland allowed action to be taken in areas of prevention and legal enforcement. The non-confidential data of the register was yearly published in lists.

Conditions of sale and purchase were largely dependent on the overall toxicity of the product. In addition, bans or specific restrictions were enacted on approximately 30 very toxic substances or groups of substances, such as arsenic, benzene, lead or cadmium by an individual ordinance. These strict regulations, especially for products for public use, resulted in a general detoxification of products, in the sense that producers strived to substitute or reduce chemicals that would provoke sales restrictions.

Initially, solely the particular acute oral lethal doses determined in small animals (usually rats) were used for classification of substances. Progress in toxicological science revealed the need to introduce additional end-points to the risk evaluation, including subchronic and chronic toxicity, corrosion, irritation and sensitisation. Due to lack of data and resources it became more and more difficult to assess all chemicals on the market on an equally broad data basis, according to the original aim and the law. Furthermore, the large majority of registrants were not ready to submit additional data, especially from animal studies, or data generally differing from $\mathrm{EC}$ requirements, to Swiss authorities

The Swiss Toxicity Law was intended to ensure protection of human health against chemical risks by strict regulations and governmental supervision of the market. However, due to the huge number of chemicals and the Swiss chemicals industry being geared to the requirements of European 
legislation, the original intention to closely control trade in toxic chemicals could not be sustained. The lack of knowledge concerning the toxicity of substances marketed before 1981 was equal to that within Europe. This demonstrates the general problems and even impossibility to maintain nation-specific regulations in areas of extensively used global markets. Based on the fact that the original vision of the Swiss Toxicity Law could not be realized, together with the barriers in trade caused in particular by the differing labelling systems led to the decision of the Federal Council to abandon the Swiss Toxic Law. In August 2005 Switzerland adopted the new Chemicals regulations that are largely harmonised with the European legislation. Europe is by far the most important trade partner for the Swiss chemical industry. Luckily and most relevant in view of consumer protection the product register is still maintained. In contrast, marketing provisions had to be greatly liberalised to be harmonized with the EC legislation. However, in light of a high level of consumer protection two distinctive provisions have been kept. Particularly dangerous substances and preparations [16] are excluded from self-service and their supply is restricted to persons sui juris.

\section{Future Challenges}

The vision of REACH to control the production, import and use of chemicals in Europe by a system that provides sufficient and concise information about chemicals and which ensures that the important information gets to those using chemicals, is most appealing. Its success, however, will greatly depend on how it will be implemented and enforced. Many detailed provisions and technical guidance documents still have to be developed. Industry, as well as authorities and consumers are sceptical about its workability in specific areas. When Switzerland adopted the EC-harmonized new legislation in 2005, the public reaction was surprise about the shared responsibilities between authorities and industry introduced by the self-regulation [17]. The fact that under the former Swiss Toxicity law each dangerous preparation was registered and controlled by authorities provided confidence to the public. Industry's responsibilities under REACH go much beyond the current self-regulation. The main responsibility for chemical safety in Europe will lay with the manufacturer and importer. Close and transparent collaboration between industry, authorities and the Agency will be essential to gaining the public's trust in the new system and thereby make REACH work.

The adoption of REACH within the EU will lead to discrepancies in EC and Swiss legislations again and thereby possibly re- introduce barriers of trade. When the Federal Government decided to reform the free market system, it was decided also to abolish unnecessary barriers of trade. Thereby it was hoped that more goods would be made available at lower prices. Against this background, Switzerland is reconsidering its current chemicals legislation and policy. Any amendments introduced should, in respect to consumer protection not result in a decrease in the level of protection of human health.

\section{Acknowledgments}

We thank F. Blunier for excellent administrative assistance, A. Däppen for interesting discussions and proofreading the manuscript, as well as $\mathbf{K}$. Melua for general support of one of us.

Received: August 14, 2006

[1] COMMISSION OF THE EUROPEAN COMMUNITIES. Proposal for a REGULATION OF THE EUROPEAN PARLIAMENT AND OF THE COUNCIL concerning the Registration, Evaluation, Authorisation and Restriction of Chemicals (REACH), establishing a European Chemicals Agency and amending Directive 1999/45/EC and Regulation (EC) \{ on Persistent Organic Pollutants $\}$ Proposal for a DIRECTIVE OF THE EUROPEAN PARLIAMENT AND OF THE COUNCIL amending Council Directive 67/548/ EEC in order to adapt it to Regulation (EC) of the European Parliament and of the Council concerning the registration, evaluation, authorisation and restriction of chemicals. COM 20030644 (03), http://europa.eu/eur-lex/en/com/pdf/2003/ com2003_0644en.html.

[2] Swiss Federal Law on Trade in Toxic Substances (Toxicity Law). AS 1972430.

[3] European Council Directive 67/548/EEC of 27 June 1967 on the approximation of laws, regulations and administrative provisions relating to the classification, packaging and labelling of dangerous substances, $O J$ 16.08.1967, P 196, 1-98.

[4] European Council Directive 76/769/EEC of 27 July 1976 on the approximation of the laws, regulations and administrative provisions of the Member States relating to restrictions on the marketing and use of certain dangerous substances and preparations, $O J$ 27.09.1976, L 262, 201-203.

[5] Council Directive 79/831/EEC of 18 September 1979 amending for the sixth time Directive 67/548/EEC on the approximation of the laws, regulations and administrative provisions relating to the classification, packaging and labelling of dangerous substances, OJ 15.10.1979, L 259, 10-28.

[6] European Council Directive 92/32/EEC of 30 April 1992 amending for the seventh time Directive $67 / 548 / \mathrm{EEC}$ on the approximation of the laws, regulations and administrative provisions relating to the classification, packaging and labelling of dangerous substances, $O J$ 05.06.1992, $L$ 154, 1-29.

[7] European Council Regulation (EEC) No 793/93 of 23 March 1993 on the evaluation and control of the risks of existing substances, OJ 05.04.1993, L 084, 1-75.

[8] Council Directive 73/173/EEC of 4 June 1973 on the approximation of Member States' laws, regulations and administrative provisions relating to the classification, packaging and labelling of dangerous preparations (solvents), $O J 11.07 .1973, L$ 189, 7-29.

[9] Council Directive 77/728/EEC on the classification, packaging and labelling of paints, varnishes, printing inks, adhesives and similar products, $O J$ 28.11.1977, $L$ $303,23-32$

[10] European Council Directive 88/379/EEC of 7 June 1988 on the approximation of the laws, regulations and administrative provisions of the Member States relating to the classification, packaging and labelling of dangerous preparations, $O J 16.07 .1988, L$ 187, 14-30.

[11] C. Bodar, J. de Bruijn, T. Vermeire, P. van der Zandt, in 'Human and Ecological Risk Assessment', Ed. Taylor \& Francis, 2002, Vol. 8, No. 7, 1825 .

[12] European Classification and Labelling Inspections of Preparations, including Safety Data Sheets, ECLIPS Report 2004 , www.cleen-eu.net.

[13] Regulation (EC) No 648/2004 of the European Parliament and of the Council of 31 March 2004 on detergents, OJ 08.04.2004 L 104, 1-35.

[14] H. Greim, M. Arand, H. Autrup, H.M Bolt, J. Bridges, E. Dybing, R. Glomot, V. Foa, R. Schulte-Hermann, Arch. Toxicol. 2006, 80,121

[15] Globally Harmonized System of Classification and Labelling of Chemicals (GHS), http://www.unece.org/trans/danger/publi/ ghs/ghs_rev00/00files_e.html.

[16] Substances and preparations are deemed to be particularly dangerous if they have to be labelled as very toxic, toxic, corrosive, explosive, highly flammable with R-phrases R15 or R 17, with one of the following R-phrases, which indicate additional physicochemical dangers: $\mathrm{R} 1, \mathrm{R} 4$, R 5, R 6, R 16, R 19 or R 44; dangerous to the environment with R-phrase $R 50 / 53$; or if their intended use is self-defence.

[17] Swiss Ordinance on Protection against Dangerous Substances and Preparations (Chemicals Ordinance, ChemO), SR 813.11. 